\title{
Penatalaksanaan Malformasi Adenomatosa Kistik Kongenital: Sebuah Laporan Kasus Berbasis Bukti
}

\author{
Maida Tanara ${ }^{1}$, Dhama Shinta ${ }^{1}$
}

${ }^{1}$ Divisi Bedah Toraks Kardiovaskular, Departemen Ilmu Bedah, Fakultas Kedokteran Universitas Indonesia, Rumah Sakit Cipto Mangunkusumo

\begin{abstract}
Abstrak
Latar Belakang. Malformasi Adenomatosa Kistik Kongenital (MAKK) merupakan kasus yang diketahui dengan baik, walaupun termasuk kasus jarang. MAKK dapat dikelola secara konservatif pada pasien tanpa gejala atau memerlukan tindakan pembedahan saat pasien menunjukkan gejala.

Ilustrasi kasus. Seorang anak lelaki usia satu tahun masuk di unit gawat darurat RSCM karena takipnu hilang timbul sejak usia empat bulan. Didiagnosis dengan MAKK dua bulan sebelumnya di provinsi BangkaBelitung, Indonesia. Lobektomi dilakukan dalam lima hari masa perawatan, ditemukan massa kistik dua pertiga paru kanan atas.

Metode. Penelitian ini adalah laporan kasus berbasis bukti. Basis data yang digunakan untuk pencarian literatur adalah Pubmed, Proquest, dan ScienceDirect. Kriteria inklusi adalah studi dalam bahasa Inggris atau Indonesia, dengan anak-anak di bawah 18 tahun sebagai subjek, dan artikel teks lengkap tersedia. Penilaian dilakukan menurut Oxford Center for Evidence Based Medicine 2011.

Kesimpulan. Lima studi kasus dianalisis. Tindakan bedah diindikasikan pada pasien simptomatik sesegera mungkin, dan pada beberapa pasien tanpa gejala sebelum usia satu tahun untuk perkembangan paru-paru yang lebih baik. Pasien yang menjalani torakoskopik adalah mereka dengan kasus yang tidak terlalu rumit dan karenanya tidak ada laporan mortalitas.
\end{abstract}

Kata kunci. Malformasi Adenomatoid Kistik Kongenital, Lobektomi, Hipertensi Pulmonal (ISSN 2723-7494 J Bedah Indonesia. 2021;49:40-39)

Korespondensi Penulis:

dr. Maida Tanara

Divisi Bedah Toraks Kardiovaskular, Departemen Ilmu Bedah

Fakultas Kedokteran Universitas Indonesia, Rumah Sakit Cipto Mangunkusumo

Email : dr.maida.tan@gmail.com 


\section{Pendahuluan}

Malformasi adenomatosa kistik kongenital (MAKK) merupakan gangguan perkembangan paru ditandai adanya massa intratorakal yang mengalami perkembangan baik padat maupun kistik, non-herediter terdiri dari jaringan paru displastik dan proliferasi struktur bronkoalveolar yang merupakan percabangan abnormal dari bronkiolus terminal yang belum sempurna atau proliferasi bronkial (epitel kuboid) yang menggantikan jaringan normal paru pada tahap awal morfogenesis pembentukan paru sehingga bermanifestasi berkurangnya jumlah alveolus normal. ${ }^{1,2}$ Insidensi kasus ini bervariasi antara 1:25000 hingga 1:35000 dari kelahiran hidup. Biasanya terjadi pada satu lobus, jarang bilateral, terjadi pada anak laki-laki sama dengan perempuan.

Pada tahun 1977, Stocker dkk menjelaskan jenis-jenis lesi paru berdasarkan diameter kistanya, yang dapat memberikan gambaran asal dari lesi-lesi displastik tersebut pada percabangan bronkial Tipe $0 .^{1-3}$ Merupakan tipe asinar displasia atau agenesis, sangat jarang terjadi. Tipe ini melibatkan semua lobus paru-paru. Tipe I. Merupakan kelainan yang terdapat pada bagian proksimal dari percabangan bronkial dan bronkiolus utama. Tipe yang terjadi paling banyak (50\% dari total kasus postnatal), makrokistik (diameter 2-20 cm), jumlah kista tunggal ataupun multipel dengan terdiri dari epitel kolumnar pseudostratified bersilia yang membentuk musin. Tipe ini sering menyebabkan terjadinya kompresi mediastinum, jarang disertai dengan anomali lain dan memiliki prognosis yang baik. Tipe II. 40\% dari total kasus MAKK merupakan tipe II, terdiri dari kista kecil tunggal atau beberapa kista yang menyerupai bronkiolus, dengan diameter $<2$ cm, dilapisi oleh campuran epitel kubus hingga kolumnar bersilia, dan kuboidal. Pada bagian dasar lesinya dilapisi oleh dinding fibromuskular tipis. Tipe III. Terdiri dari kista adenomatosa mikrokistik (diameter $<0,5 \mathrm{~cm}$ ) yang didominasi oleh lesi kecil padat. Tipe ini ini mewakili 10\% dari total lesi MAKK dan secara histologis terdiri dari struktur alveolus yang terdiri dari lapisan epitel kuboidal bersilia yang dipisahkan oleh massa mikroskopis yang terdiri dari lapisan epitel kuboidal tidak bersilia. Secara makroskopik tampak sebagai massa padat tanpa terlihat adanya bentuk kista. Tipe IV memiliki karakteristik kista perifer yang berdinding tipis dan berukuran besar. Lesi ini disebabkan oleh malformasi hamartomatosus asinus distal.

Pada usia bayi hingga anak, pasien dapat datang dengan gejala infeksi saluran napas, batuk darah, dispneu, hingga 


\section{Laporan Kasus}

terkadang abses paru. Bayi dengan lesi yang besar dapat menyebabkan terjadinya insufisiensi pernapasan, terkadang disertai hipertensi pulmonal. Bila bayi lahir tanpa menunjukkan gejala, foto toraks sebaiknya ditunda hingga 12 jam setelah lahir. Dalam 12 jam pertama diharapkan sudah terjadi penyerapan air dan hasil gambaran foto toraks akan menunjukkan perbaikan. ${ }^{2,4-6} C T$ scan resolusi tinggi (HRCT) pada toraks dapat digunakan untuk visualisasi massa paru dan malformasi bronkopulmoner. ${ }^{2,7}$ USG Doppler, CT scan, atau MRI angiografi dapat digunakan untuk menentukan suplai arteri dan drainase vena pada paru-paru. ${ }^{2,8,9}$

Semua pasien MAKK perlu dilakukan evaluasi adanya indikasi tindakan pembedahan. Jika bayi terdapat gejala klinis, maka pilihannya yaitu tindakan pembedahan. Namun menjadi kontroversi dalam menentukan tatalaksana yang tepat pada anak dengan dugaan MAKK asimtomatis. Terdapat tinjauan sistematis dan meta-analisis dari berbagai literature tahun 1996-2008, yang mengidentifikasi 41 studi dengan total 1070 kasus. Angka komplikasi dari kasus asimptomatik pada periode neonatus adalah $\pm 3,2 \%$, yang terjadi pada rerata usia 7 bulan., ${ }^{2,10}$ Namun, beberapa dari anak dengan riwayat MAKK asimtomatis dapaat terjadi komplikasi yang mengancam jiwa. Operasi elektif dapat mengurangi komplikasi pascabedah yang signifikan jika dibandingkan dengan operasi darurat. ${ }^{2,10,11}$ Sebagian besar pasien melalui pembedahan dalam bentuk lobektomi atau pneumektomi pada usia satu hingga dua tahun karena meningkatnya risiko adenoma. $^{2}$ Penelitian tentang MAKK di Rumah Sakit Cipto Mangunkusumo terbatas, sehingga penulis merasa perlu mencari literatur dan analisis pada pengobatan MAKK.

\section{Ilustrasi kasus}

Kasus merupakan anak laki-laki usia satu tahun datang ke Instalasi gawat darurat (IGD) dengan sesak napas. Sesak napas dialami hilang timbul sejak usia empat bulan. Diagnosis malformasi adenomatosa kistik kongenital ditegakkan di RSUD Pangkal Pinang, Bangka-belitung saat usia sembilan bulan. Pasien lalu dirujuk ke IGD RSUPN dr. Cipto Mangunkusumo dengan batuk pilek dan demam sehari sebelum masuk rumah sakit. Foto polos toraks hemitoraks kanan hiperlusen dengan corakan paru minimal, disertai herniasi paru ke kiri dan pendesakan struktur-struktur mediastinum ke kiri. Pemeriksaan echocardiogram tidak terdapat kelainan.

Dilakukan lobektomi superior melalui insisi torakotomi posterolateral kanan pada hari kelima perawatan. Ditemukan massa kistik pada dua pertiga 


\section{Laporan Kasus}

lobus superior paru kanan dengan jaringan paru kanan normal minimal, lobus media dan inferior paru kanan tampak normal intraoperasi. Selama tiga hari di perawatan intensif pascaoperasi, kemudian rawat jalan setelah hari ke lima pascaoperasi. Gambaran histologik sesuai dengan jaringan paru dengan peradangan akut dan kronik serta pembentukan bula yang dapat ditemukan pada malformasi adenomatoid kistik kongenital.

\section{Metode}

Penelitian ini adalah laporan kasus berbasis bukti. Basis data yang digunakan untuk pencarian literatur adalah Pubmed, Proquest, dan ScienceDirect menggunakan kata kunci "Malformasi Adenomatoid Kistik Kongenital", "Lobektomi", NOT "Hipertensi Pulmonal" Kriteria inklusi adalah studi dalam bahasa Inggris atau Indonesia, dengan anak-anak di bawah 18 tahun sebagai subjek, dan artikel teks lengkap tersedia. Penilaian dilakukan menurut Oxford Center for Evidence Based Medicine 2011.

\section{Hasil}

Setelah pencarian literatur, ditemukan 5 artikel sesuai pada (tabel 2)
Pada penelitian Garzi dkk (2019), melaporkan tiga kasus MAKK tipe II yang diobservasi di Departemen Bedah Anak, Universitas Siena. Kasus pertama bayi perempuan, pada usia 14 jam dilakukan operasi untuk memperbaiki atresia esofagus. Pada usia dua hari didapatkan adanya lesi multikistik pada lobus kanan inferior sehingga menyebabkan takipnea sianosis, dilakukan torakotomi reseksi segmental lobus inferior kanan. Pasien pulang pada usia satu bulan, observasi hingga usia enam tahun fungsi pernapasan baik. Kasus kedua anak laki-laki, ditemukan lesi kistik pada paru kanan inferior dari pemeriksaan antenatal, dilakukan observasi pada usia dua, enam dan 15 minggu terdapat pengurangan ukuran lesi. Dilakukan torakotomi lobektomi inferior kanan pada usia 24 bulan, pasien pulang setelah 20 hari pascaoperasi. Kasus ketiga anak perempuan, didapatkan lesi kistik pada lobus kiri inferior pada usia 8 hari. Dilakukan torakoskopik konversi torakotomi reseksi lobus inferior kiri pada usia tiga tahun. ${ }^{12}$

Chong dkk (2016) melaporkan satu kasus bayi didapatkan lesi hiperlusen pada paru kanan saat usia sembilan hari. Dilakukan observasi hingga usia 24 hari kondisi menurun sehingga dilakukan torakotomi lobektomi lobus medial kanan. Pasien pulang setelah tiga minggu pascaoperasi. ${ }^{13}$ 


\section{Laporan Kasus}

Chen dkk (2010, melaporkan 16 kasus yang didiagnosis MAKK dan/atau BPS di National Taiwan University Hospital pada Juli 1995 sampai Januari 2008. Delapan pasien (50\%) dengan MAKK, 5 pasien (31\%) dengan BPS, dan tiga pasien (19\%) dengan lesi campuran. Median usia kehamilannya adalah 38 minggu (32-41 minggu) dan median berat badan lahirnya adalah 3189 gram (1766-4090 gram). Sebanyak 13 kasus (81\%) terdiagnosis pada periode prenatal dengan median usia kehamilan pada 20 minggu (20-24 minggu), dan sisanya terdiagnosis pada minggu pertama pascakelahiran. Pada pemeriksaan USG ditemukan adanya lesi paru makrokistik atau mikrokistik. Pemeriksaan sonografi serial pada periode antenatal menunjukkan sebanyak 11 kasus (85\%) lesi tersebut mengalami regresi, 1 kasus $(7.5 \%)$ dengan lesi yang stabil, dan 1 kasus (7.5\%) lesi mengalami progresi. Reseksi bedah dilakukan pada 7 (88\%) pasien yang bergejala dan pada $4(50 \%)$ pasien yang asimtomatis. Operasi pada pasien dengan gejala dilakukan berdasarkan tingkat keparahan gangguan pernapasan dan episode infeksinya. Median usia dilakukannya operasi adalah 11 hari (5-169 hari). Sebanyak sepuluh pasien dilakukan torakotomi, 1 pasien dilakukan videoassisted thoracic surgery (VATS). Metode operasi berupa lobektomi pada delapan pasien dan sekuestrektomi pada tiga pasien. Seluruh pasien dilakukan pemantauan secara teratur selama 1-8 tahun. Seluruh pasien yang dilakukan pembedahan tidak ditemukan adanya penyakit dan keterbatasan dalam aktivitas sehari-hari. Begitu juga dengan lima pasien yang tidak dilakukan pembedahan tetap dalam kondisi asimtomatis selama periode pemantauan. Tidak ditemukan juga terjadinya transformasi keganasan pada pasien serial kasus ini. ${ }^{14}$

Francesco dkk (2013) menunjukkan pada 54 pasien dengan malformasi paru kongenital dilakukan lung-sparing surgery yang dilakukan di Departemen Bedah Anak, Universitas Bologna pada Januari 2001 sampai Desember 2010. Operasi dilakukan pada rentang usia 16 hari sampai 14 tahun. Sembilan pasien memiliki gejala sebelum dilakukannya operasi, enam pasien dengan gangguan pernapasan pada neonatus, dan 3 pasien dengan pneumonia bakterialis (pada usia 15, 48 dan 60 bulan). Sebanyak 46 pasien (85\%) dilakukan formal muscle sparing thoracotomy (28 primer, 18 konversi setelah torakoskopi). 26 dari 54 dilakukan pendekatan torakoskopi awal, dengan 8 kasus sukses dilakukan. Lima puluh pasien dilakukan wedge resection dan empat pasien dilakukan segmentektomi anatomikal. Pasien pulang setelah rata-rata perawatan selama delapan hari. Tidak 


\section{Laporan Kasus}

ditemukan perbedaan yang signifikan pada insidensi terjadinya komplikasi pada prosedur torakotomi dan prosedur videothoracoscopic $(3 / 28$ vs $5 / 26, p>0,05) .{ }^{15}$

Polites dkk (2016) menunjukkan sebanyak 1120 anak yang berusia $\leq 20$ tahun dilakukan reseksi untuk penyakit paru kongenital. Sebanyak $679(60,6 \%)$ pasien dilakukan open torakotomi, dan 441 (39,4\%) dilakukan torakoskopi. Hanya terdapat 6,9\% anak yang dilakukan reseksi langsung setelah kelahiran pada masa perawatan di rumah sakit, $68,8 \%$ dilakukan reseksi di usia $<1$ tahun. Prosedur yang paling sering dilakukan adalah lobektomi (56,6\%) dengan $67,5 \%$ dilakukan open surgery dan 51,6\% dilakukan reseksi sub-lobar ( $\mathrm{p}<0,001)$. Tidak terdapat perbedaan lamanya masa perawatan pascaoperasi dan komplikasi antara pasien yang dilakukan torakoskopi dan open lobektomi dan reseksi sub-lobar. Laju mortalitas juga rendah, yaitu $<10$ kematian yang terjadi pada pasien yang dilakukan open procedure dan tidak ditemukan adanya kematian pada pasien yang dilakukan torakoskopi. ${ }^{16}$

\section{Diskusi}

Pada kasus yang diilustrasikan tidak dilakukan diagnostik secara antenatal. Diagnostik ditegakkan pada usia sembilan bulan namun tatalaksana dilakukan saat usia satu tahun saat diterima di RS dr. Cipto Mangunkusumo. Tindakan yang dilakukan sama dibandingkan dengan literatur yang ditemukan berupa lobektomi pada pasien dengan gejala berupa sesak, namun pada kasus tidak ditemukan adanya hipertensi pulmonal yang biasanya menyertai penderita yang terlambat dioperasi. Pascaoperasi dirawat selama tiga hari di perawatan intensif, kemudian rawat jalan setelah hari ke lima pascaoperasi. Tindakan operasi pada kasus malformasi adenomatosa kistik kongenital baiknya dilakukan sebelum usia satu tahun dan pertumbuhan paru-paru dapat dikejar lebih baik jika dilakukan torakotomi sejak dini. Penatalaksanaan torakotomi lobektomi pada malformasi adenomatosa kistik kongenital pada kasus yang dilaporkan didukung studi dengan level of evidence 3 dan 4. 


\section{Daftar Pustaka}

1. Cruz-Martínez R, Cruz-Lemini M, Gratacós E. Congenital cystic adenomatoid malformation of the lung. Obstet Imaging Fetal Diagnosis Care, 2nd Ed. 2017;2:1316.e1.

2. Kotecha S, Barbato A, Bush A, Claus F, Davenport M, Delacourt C, et al. Antenatal and Postnatal Management of Congenital Cystic Adenomatoid Malformation. Paediatr Respir Rev. 2012;13(3):162-71.

3. Stocker JT, Madewell JE DR. Congenital cystic adenomatoid malformation of the lung. Classification and morphologic spectrum. Hum Pathol. 1977;8:15571.

4. Azizkhan RG, Crombleholme TM. Congenital cystic lung disease: Contemporary antenatal and postnatal management. Pediatr Surg Int. 2008;24(6):643-57.

5. Biyyam DR, Chapman T, Ferguson MR DGD. Congenital lung abnormalities: embryologic features, prenatal diagnosis, and postnatal radiologic-pathologic correlation. Radiographics. 2010;30:1721-38.
6. Epelman M, Kreiger PA, Servaes S, Victoria T, Hellinger JC. Current imaging of prenatally diagnosed congenital lung lesions. Semin Ultrasound, CT MRI. 2010;31(2):141-57.

7. Hang JD, Guo QY, Chen CX, Chen LY. Imaging approach to the diagnosis of pulmonary sequestration. Acta radiol. 1996;37(6):883-8.

8. Wang S, Ruan Z, Liu F, Huang H, Song K. Pulmonary Sequestration: Angioarchitecture Evaluated by Three-Dimensional Computed Tomography Angiography. Thorac Cardiovasc Surg. 2010;58:354-6.

9. Abbey P, Das CJ, Pangtey GS, Seith A, Dutta R, Kumar A. Imaging in bronchopulmonary sequestration. J Med Imaging Radiat Oncol. 2009;53:22-31.

10. Stanton M, Njere I, Ade-Ajayi N, Patel S, Davenport M. Systematic review and meta-analysis of the postnatal management of congenital cystic lung lesions. J Pediatr Surg. 2009;44(5):1027-33.

11. Davenport M, Warne SA, Cacciaguerra S, Patel S, Greenough A, Nicolaides K. Current Outcome of Antenally Diagnosed Cystic Lung 


\section{Laporan Kasus}

Disease. J Pediatr Surg. children in the United States. J 2004;39(4):549-56. Pediatr Surg. 2016;51(7):1101-5.

12. Garzi A, Ferrentino U, Ardimento G, Brongo S, Rubino MS, Calabrò E, et al. Congenital cystic adenomatoid malformation of the lung tipe II: three cases report. Transl Med. 2019;20(2):4-8.

13. Chong Y, Rhee YJ, Han SJ, Cho HJ, Kang SK, Kang MW. Lifethreatening congenital cystic adenomatoid malformation in the premature neonate. Korean J Thorac Cardiovasc Surg. 2016;49(3):210-3. 14. Chen HW, Hsu WM, Lu FL, Chen PC, Jeng SF, Peng SSF, et al. Management of congenital cystic adenomatoid malformation and bronchopulmonary sequestration in newborns. Pediatr Neonatol. 2010;51(3):172-7.

15. Fascetti-Leon F, Gobbi D, Pavia SV, Aquino A, Ruggeri G, Gregori G, et al. Sparing-lung surgery for the treatment of congenital lung malformations. J Pediatr Surg. 2013;48(7):1476-80.

16. Polites SF, Habermann EB, Zarroug AE, Thomsen KM, Potter DD. Thoracoscopic Vs open resection of congenital cystic lung diseaseutilization and outcomes in 1120 


\section{Daftar Tabel dan Gambar}

Tabel 1. Klasifikasi malformasi paru kongenital.
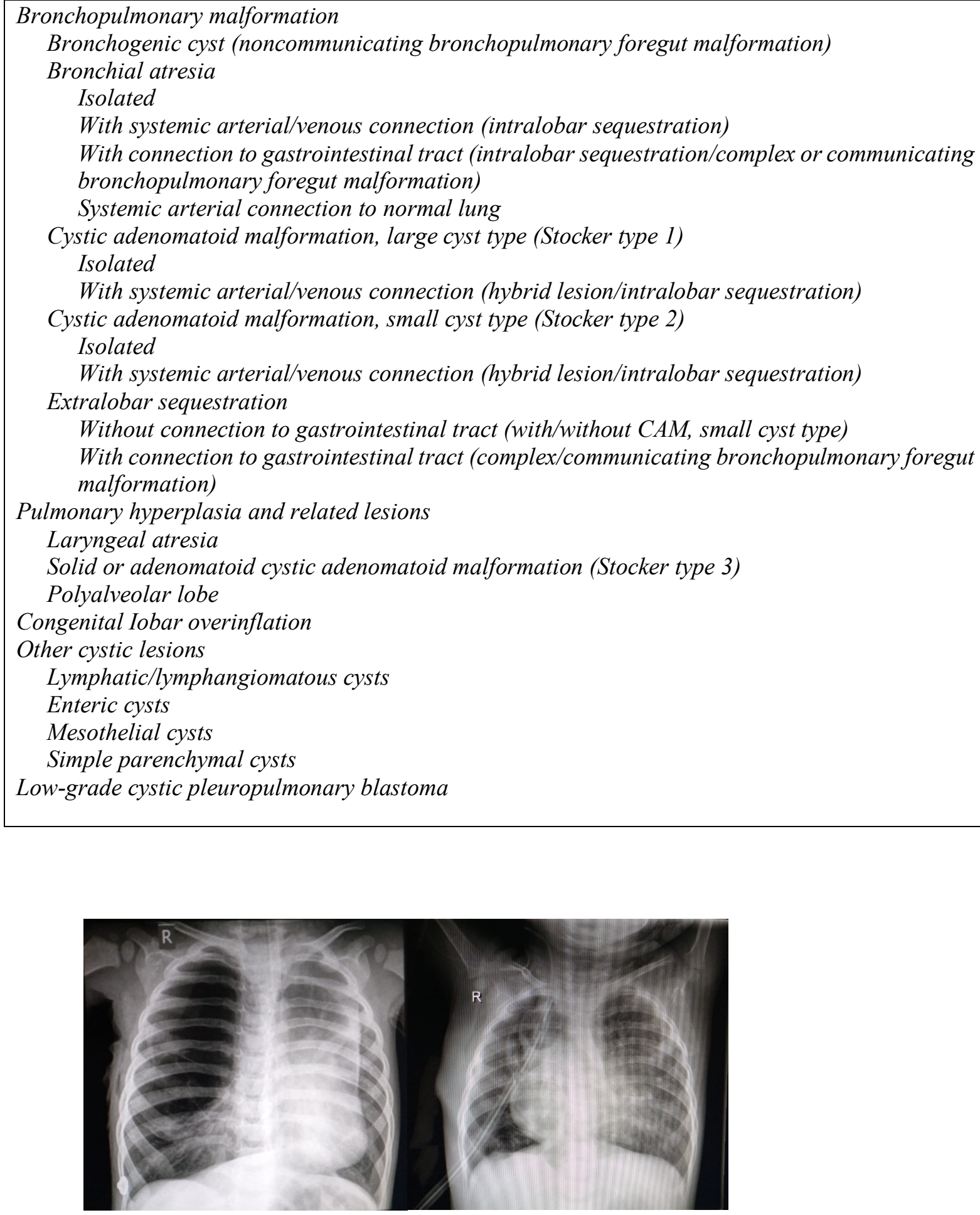

Gambar 1. a) foto toraks menunjukkan hiperlusen paru kanan atas. b) foto toraks 5 hari pascaoperasi 
Tabel 2. Karakteristik dan hasil studi yang diulas

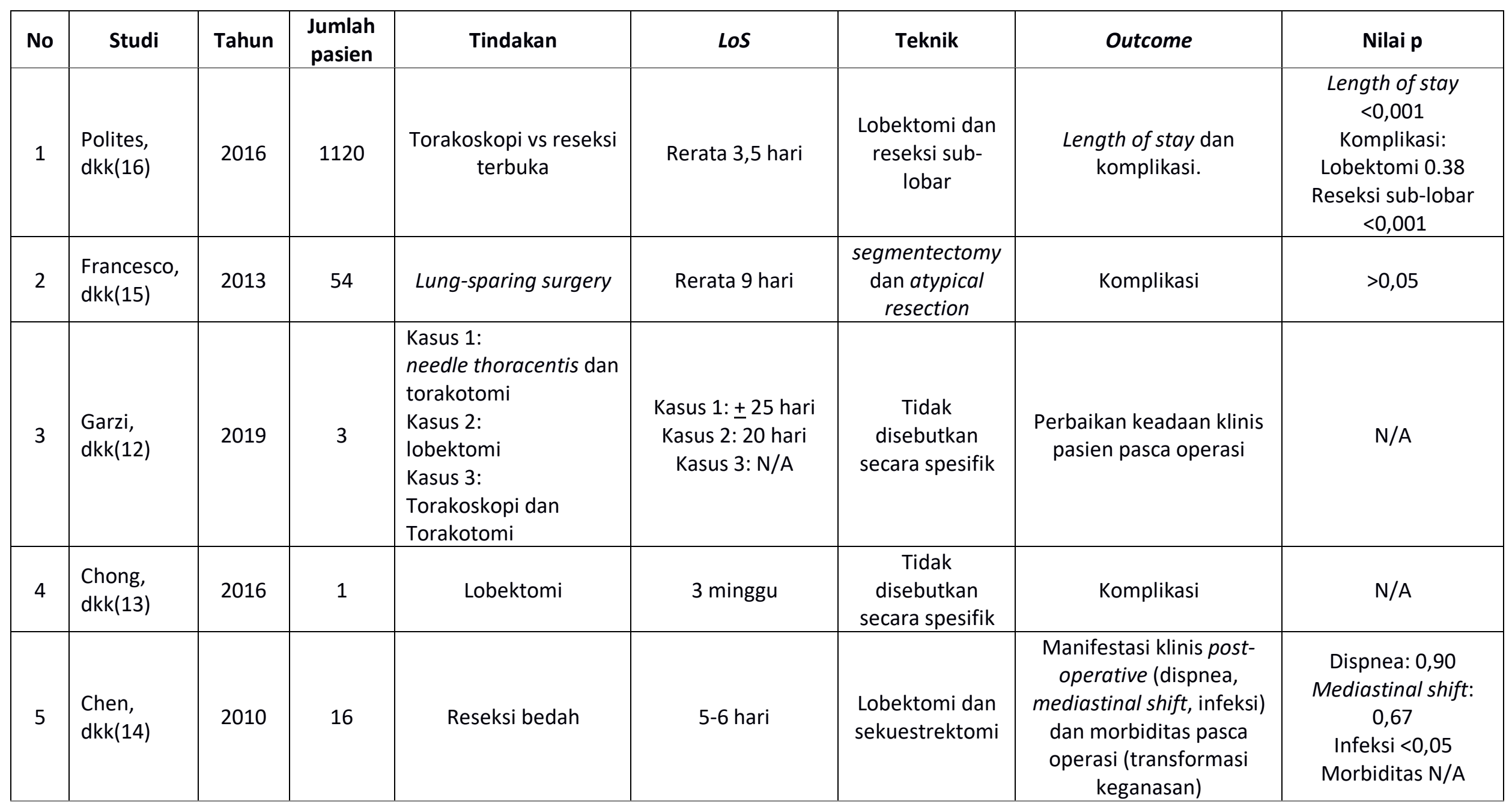

